\title{
A proof-of-concept study evaluating the effect of ADX10059, a metabotropic glutamate receptor-5 negative allosteric modulator, on acid exposure and symptoms in gastro-oesophageal reflux disease
}

\author{
C Keywood, ${ }^{1}$ M Wakefield, ${ }^{1}$ J Tack ${ }^{2}$
}

\begin{abstract}
Competing interests: Declared (the declaration can be viewed on the Gut website at http://gut. bmi.com/content/vol58/issue9).

${ }^{1}$ Addex Pharma, Plan-lesOuates, Switzerland:

${ }^{2}$ Department of Gastroenterology, University of Leuven, Leuven, Belgium
\end{abstract}

Correspondence to: Dr C Keywood, Addex Pharma SA, Plan-les-Ouates, CH-1228

Switzerland

charlotte.keywood@

addexpharma.com

Revised 19 April 2009 Accepted 21 April 2009

Published Online First

20 May 2009

\section{UNLOCKE}

This paper is freely available online under the BMJ Journals unlocked scheme, see http:// gut.bmj.com/info/unlocked.dt

\section{ABSTRACT}

Background: In preclinical models, antagonism of metabotropic glutamate receptor 5 (mGluR5) reduces transient lower oesophageal sphincter relaxations (TLOSRs) and increases LOS pressure. This study evaluated the effect of ADX10059, a potent, selective, negative allosteric modulator of mGluR5, on oesophageal pH-metry and clinical symptoms in GORD.

Methods: Two groups of patients with GORD ( $n=12$ per group) underwent 24-h oesophageal pH-metry on two sequential treatment days. The patients received oral placebo three times daily (tds) 30 min before a high-fat meal on Day 1 and oral ADX10059 50 mg (Group 1) or $250 \mathrm{mg}$ (Group 2) tds $30 \mathrm{~min}$ before a high-fat meal on Day 2. The primary variable was acid exposure (\%time $\mathrm{pH}<4$ ). Secondary variables included number and duration of reflux episodes, number and duration of symptomatic episodes and symptoms recorded in diaries. Comparisons were made for Day 2 (active) versus Day 1 (placebo) treatment and for Group 1 versus Group 2.

Results: ADX10059 $250 \mathrm{mg}$ tds significantly decreased the percentage of time with $\mathrm{pH}<4$ from $7.2 \%$ to $3.6 \%$ $(p=0.01)$. ADX10059 $250 \mathrm{mg}$ tds reduced pH-metrymeasured oesophageal acid exposure, throughout the $24 \mathrm{~h}$ period, nocturnally and postprandially, and significantly reduced the number and duration of symptomatic reflux episodes $(p=0.03)$. ADX10059 $50 \mathrm{mg}$ tds was not significantly superior to placebo. ADX10059 was generally well tolerated.

Conclusion: The mGluR5 negative allosteric modulator ADX10059 reduced acid reflux which was associated with improvement in clinical symptoms in patients with GORD. ADX10059 appears to have a potential role in the clinical management of GORD.

Proton pump inhibitors (PPIs) are the cornerstone of medical therapy for gastro-oesophageal reflux disease (GORD) ${ }^{1-3}$ However, it has been estimated that up to $30 \%$ of patients with GORD remain symptomatic on standard dose (once daily) of PPIs ${ }^{4-8}$ and the majority of these will continue to experience GORD symptoms on even higher doses of PPIs. ${ }^{48}$ Hence, there is a need for novel therapeutic approaches to GORD.

The most frequent mechanism underlying reflux events is transient lower oesophageal sphincter relaxation (TLOSR), which is an attractive target for the treatment of GORD. ${ }^{9}$ TLOSRs involve a vago-vagal reflex pathway which is activated by gastric distension and integrated in the brain stem to result in relaxation of the lower oesophageal sphincter smooth muscle. A wide variety of transmitters and receptors are expressed centrally and peripherally in the vagal pathway that mediates lower oesophageal sphincter control. ${ }^{9-11}$

Glutamate is the primary neurotransmitter involved in signalling from visceral and somatic primary afferents to the central nervous system. ${ }^{11}$ Anatomical studies of vagal afferents have revealed expression of metabotropic glutamate receptors (mGluRs), including mGluR5, in the nodose ganglia of several species, including humans, and evidence suggests possible localisation in peripheral gastric vagal afferent terminals. ${ }^{11}$ Recent studies in animal models identified selective antagonists of mGluR 5 as potent inhibitors of TLOSRs and reflux episodes. ${ }^{12} 13$ It has been argued that peripheral mGluR5, expressed in gastro-oesophageal vagal afferent endings, plays a more prominent role in control of TLOSRs as compared with central mGluR $5 .{ }^{10}$ These preclinical findings support a role for mGluR5 in the direct control over TLOSRs, providing a mechanistic basis for the clinical development of mGluR5 antagonists for the treatment of GORD.

ADX10059 is a potent selective negative allosteric modulator of the mGluR5 receptor. Rather than acting directly by blocking the glutamate orthosteric binding site, ADX10059 modulates the activity of the mGluR5 receptor by binding to a site distinct from the glutamate binding site (ie, an allosteric site), and diminishes the intra-cellular signal created when glutamate binds to the receptor. The inhibitory effects of a negative allosteric modulator, unlike an orthosteric inhibitor, are non-competitive. Hence, the magnitude and duration of effect of a negative allosteric modulator are not determined solely by its pharmacokinetics. As the negative allosteric modulator acts dynamically with the natural ligand on the receptor function, the effect is more a modulation of physiological responses.

As well as being expressed in the gastrointestinal tract, mGluR5 expression is predominant in areas of the mammalian brain involved in emotional processes, such as the dentate gyrus regions within the hippocampus, regions of the basal ganglia (striatum and nucleus accumbens) and in the dorsal horn of the spinal cord, suggesting a role for these receptors in affective disorders such as anxiety and depression. ${ }^{14}{ }^{15}$ The mGluR5 is also implicated in central pain processing pathways in the trigeminal nucleus caudalis and spinothalamic tract. ADX10059 is also centrally effective, and is 
additionally being tested in the treatment of migraine. Effects on emotion centres and central pain processing may also be of relevance in the symptomatic treatment of GORD. The present study was a proof-of-concept study aimed at investigating the efficacy, safety and tolerability of the selective mGluR5 antagonist ADX10059 in reducing acid reflux and clinical symptoms in symptomatic patients with GORD.

\section{MATERIALS AND METHODS}

\section{Study design and objectives}

The study was a randomised, single (patient)-blind, placebocontrolled, sequential treatment trial in patients with GORD. The duration of the trial was approximately 4-5 weeks per subject and comprised three visits: screening (Visit 1), two consecutive study treatment days, (placebo followed by active treatment, Visit 2), and a follow-up visit (Visit 3) 1-2 weeks after dosing. As each patient received both placebo and active treatment he/she acted as his/her own control.

The primary objective of the study was to explore the effect of ADX10059 on oesophageal acid exposure measured by $24 \mathrm{~h}$ oesophageal $\mathrm{pH}$ monitoring. The secondary objectives of the study were: (1) to explore the effect of ADX10059 on diurnal, nocturnal and postprandial episodes of acid reflux; (2) to evaluate the effect of ADX10059 on clinical symptoms of reflux; (3) to evaluate the safety and tolerability of ADX10059 in patients with GORD; and (4) to evaluate the $0-4 \mathrm{~h}$ post-dose plasma concentrations of ADX10059 in patients with GORD.

\section{Conduct of the study}

The study was conducted in a single centre (SGS Aster, Paris, France) in an inpatient setting and was performed in accordance with the ethical principles stated in the Declaration of Helsinki as revised by $52 \mathrm{nd}$ General Assembly in Edinburgh, 2000, and with the French Huriet law. After Ethics Committee approval, the study was conducted between September and November 2006 in accordance with Good Clinical Practice (GCP) and standard operating procedures (SOP) for clinical investigation and documentation in force at the clinical trial centre.
Table 1 Demographic characteristics of the patients

\begin{tabular}{lll}
\hline Characteristic & Group 1 (n= 12) & Group 2 (n= 12) \\
\hline Race (Caucasian) & $12(100 \%)$ & $12(100 \%)$ \\
Sex (female) & $3(25 \%)$ & $2(16.7 \%)$ \\
Age (years) & 44.6 & 45.1 \\
Weight $(\mathrm{kg})$ & 77.9 & 79.8 \\
Body mass index $\left(\mathrm{kg} / \mathrm{m}^{2}\right)$ & 26.1 & 26.2 \\
Light smokers $(<5$ cigarettes/day) & $3(25.0 \%)$ & $2(16.7 \%)$ \\
Previous GORD medications & $6(50 \%)$ & $10(83.3 \%)$
\end{tabular}

GORD, gastro-oesophageal reflux disease.

\section{Patients}

The patients were recruited from a specialist gastroenterology clinic in Paris. All patients had a prior diagnosis of symptomatic GORD made by a gastroenterologist and all had to have a history of good control of heartburn, regurgitation and other GORD symptoms with acid suppressant therapy. Patients who were on acid suppressants at the time of screening had to stop treatment for at least 2 weeks before the study treatment days. Eligible patients were Caucasian men and women aged 18-65 years, weighing between 50 and $100 \mathrm{~kg}$ with a body mass index between 18 and $35 \mathrm{~kg} / \mathrm{m}^{2}$, who were non-smokers or light smokers $(<5$ cigarettes per day), with normal arterial blood pressure and heart rate.

Patients were excluded if they (1) had any clinically significant acute or chronic disease or significant abnormality in pre-study laboratory tests and physical examination; (2) had received any experimental drug within 30 days prior to screening; (3) were known or suspected alcohol or drug abusers; (4) had undergone surgery or had donated blood within 1 month prior to study start; or (5) had received any drug known to affect hepatic metabolism within 1 month or any drug known to affect renal tubular secretion or gastrointestinal motility, within 2 weeks prior to the first study dose administration. Patients with a history of oesophageal stricture, gastrointestinal bleeding or gastrointestinal surgery were also excluded.

Figure 1 Patient disposition.

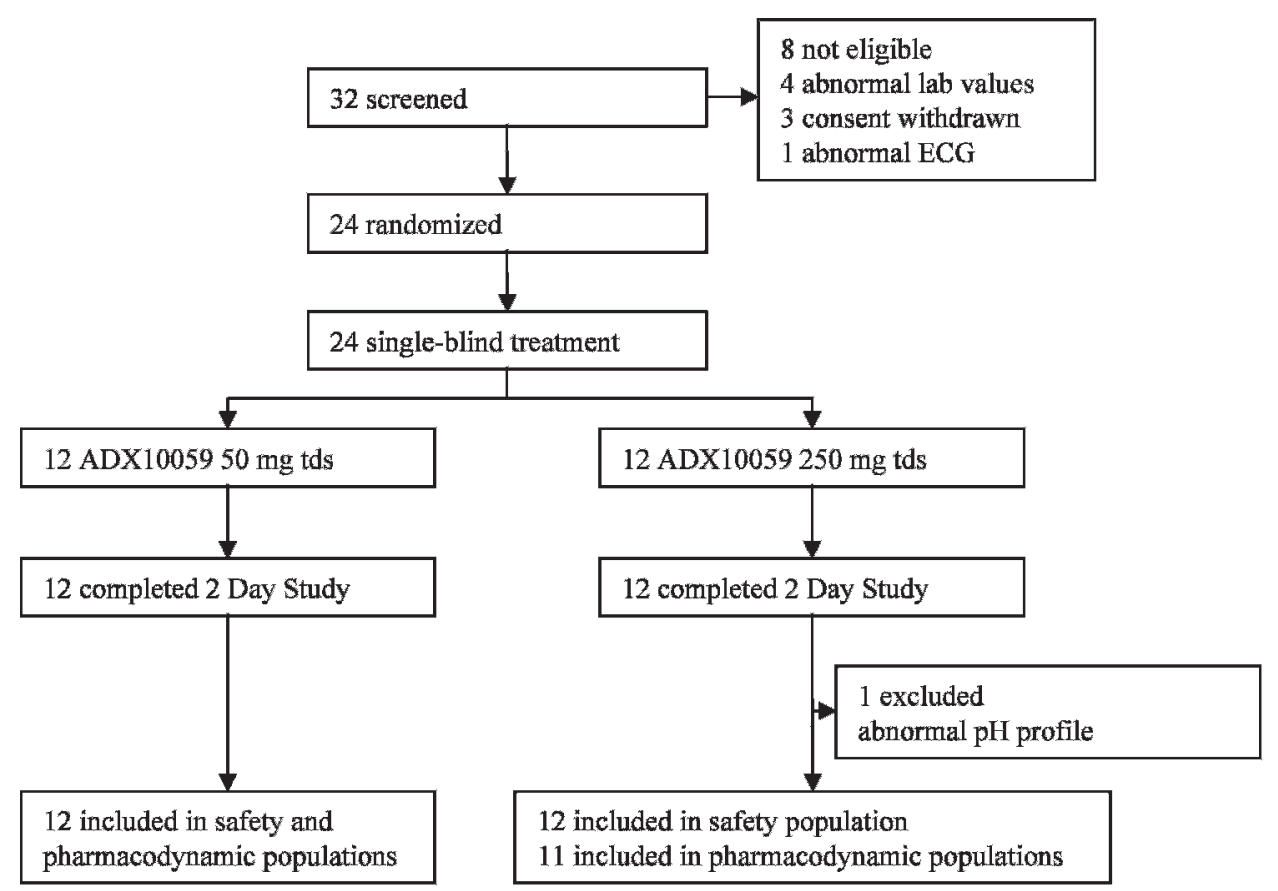




\section{Procedures}

Screening and randomisation

Within 3 weeks of the first study treatment day patients attended a screening visit. After patients had provided their written informed consent, the medical histories and demographic data were recorded and safety screening was performed. Eligible patients were randomised to one of two treatment groups: Group 1, placebo (Study Day 1) followed by ADX10059 50 mg tds (Study Day 2); or Group 2, placebo (Study Day 1) followed by ADX10059 $250 \mathrm{mg}$ tds (Study Day 2). The choice of doses was based on the pharmacokinetic and tolerability data from a previous repeated dose study in healthy subjects (ref study ADX10059-102, data on file), using the same immediate release formulation; ie, simple drug powder-filled capsules with no excipients.

\section{Study drug dosing and $\mathrm{pH}$ monitoring days}

Patients were admitted to the clinical pharmacology unit on the evening prior to study drug dosing (ie, Day -1). Prior to dosing on Study Days 1 and 2, patients fasted overnight for a minimum of $10 \mathrm{~h}$. Standardised high-fat meals were provided for breakfast, lunch and supper and patients had $30 \mathrm{~min}$ to consume each meal. To normalise intake, a fixed amount of water $(1500 \mathrm{ml})$ was supplied and was required to be consumed within each $24 \mathrm{~h}$ period. The ambulatory oesophageal $\mathrm{pH}$ monitoring was performed using an antimony $\mathrm{pH}$ electrode with a separate skin reference electrode (Digitrapper pH100; Medtronic, Tolochenas, Switzerland). The ambulatory $\mathrm{pH}$ monitoring unit was calibrated before each use, using standard buffers. The oesophageal $\mathrm{pH}$ probe was inserted via one nostril to a distance of approximately $5 \mathrm{~cm}$ above the lower oesophageal sphincter. Online continuous $\mathrm{pH}$ monitoring was used to locate the position of the lower oesophageal sphincter for each patient.

On Study Days 1 and 2 the probe was inserted and monitoring started about 10 min prior to the first dose administration. The probe was removed after approximately $24 \mathrm{~h}$. Patients had a $30 \mathrm{~min} \mathrm{pH}$ monitoring-free period, with removal of the catheter, between the two study days so that they could take a shower and change their clothes if they wished.

On each study day, the patients were administered a single oral dose of study medication on three occasions, 30 min before each meal. On Study Day 1 they received placebo, and on Study Day 2 they received ADX10059 $50 \mathrm{mg}$ (Group 1) or $250 \mathrm{mg}$ (Group 2). The patients took the capsules with $240 \mathrm{ml}$ of water at room temperature and were dosed while standing. After dosing, the patients remained on their beds, sitting at approximately 45 degrees. The patients were not allowed to lie flat for $4 \mathrm{~h}$ following the morning and midday doses, except for study procedures or if clinically indicated.

The timetable of procedures on Study Days 1 and 2 was as follows:

- 07:20 start oesophageal $\mathrm{pH}$ recording

- 07:30 study medication dose 1

- 08:00 breakfast

- 12:30 study medication dose 2

- 13:00 lunch

- 19:30 study medication dose 3

- 20:00 dinner

- 22:00 to approx 07:00 bedtime

- 07:00 approx, end of $\mathrm{pH}$ monitoring period on Day 1 (on Day 2 end of $\mathrm{pH}$ monitoring period was at 07:30)

\section{Pharmacodynamic efficacy measures}

\section{$24 \mathrm{~h}$ oesophageal $\mathrm{pH}$ measurement}

Oesophageal $\mathrm{pH}$ was recorded for approximately $24 \mathrm{~h}$ starting on Study Day 1 and Study Day 2. $\mathrm{pH}$ measurements were captured every $4 \mathrm{~s}$ resulting in approximately 21600 measurements for each $24 \mathrm{~h}$ period. Each variable was calculated for the $24 \mathrm{~h}$ recording period and for the upright diurnal period (07:30 to 22:00) and the supine nocturnal period (22:00 to 07:30 approx). The percentage time for oesophageal $\mathrm{pH}<4$ was calculated from the continuous online monitoring.

\section{Number and duration of reflux episodes}

The number and total duration of gastro-oesophageal reflux episodes was recorded. In accordance with the standards of the clinical pharmacology unit, a reflux episode was defined as seven consecutive measures with a $\mathrm{pH}<4$; ie, at least $28 \mathrm{~s}$. The total duration of reflux episodes was the sum of all actual times of reflux episodes $\geqslant 28 \mathrm{~s}$. The number of gastro-oesophageal reflux episodes and the total duration of time with gastrooesophageal reflux episodes was summarised for the $24 \mathrm{~h}$, diurnal and nocturnal periods. Oesophageal acid clearance was expressed as the mean duration of acid reflux events.

\section{Postprandial reflux episodes}

The postprandial periods were defined as the period of $4 \mathrm{~h}$ following each meal; ie, from 08:00 to 12:00, 13:00 to 17:00 and

Table 2 Percentage time when the $\mathrm{pH}$ was less than 4

\begin{tabular}{|c|c|c|c|}
\hline Treatment group & $\begin{array}{l}\text { Percentage time } \\
\mathrm{pH}<4 \text { in } 24 \mathrm{~h}\end{array}$ & $\begin{array}{l}\text { Percentage time } \\
\mathbf{p H}<\mathbf{4} \text {, diurnal }\end{array}$ & $\begin{array}{l}\text { Percentage time } \\
\text { pH }<4 \text {, nocturnal }\end{array}$ \\
\hline \multicolumn{4}{|l|}{ Group 1, $n=12$} \\
\hline Placebo & 14.9 & 9.5 & 22.7 \\
\hline ADX10059, $50 \mathrm{mg}$ & 15.1 & 12.8 & 18.9 \\
\hline Estimate change from baseline & 2.71 & 4.75 & 0.19 \\
\hline 95\% Confidence interval & -2.05 to 7.48 & 0.14 to 9.37 & -5.88 to 6.26 \\
\hline p Value & NS & $0.0442^{*}$ & NS \\
\hline \multicolumn{4}{|l|}{ Group 2, n= 11} \\
\hline Placebo & 7.2 & 5.2 & 9.7 \\
\hline ADX10059, $250 \mathrm{mg}$ & 3.6 & 3.4 & 3.7 \\
\hline Estimate change from baseline & -6.41 & -3.41 & -10.37 \\
\hline 95\% Confidence interval & -11.4 to -1.42 & -8.24 to 1.42 & -16.73 to -4.01 \\
\hline p Value & 0.0144 & NS & 0.0028 \\
\hline
\end{tabular}

*Increased compared with placebo.

NS, not significant. 
Table 3 Group 1 (ADX10059 $50 \mathrm{mg}$ tds): number and duration of reflux episodes and clinical symptoms

\begin{tabular}{|c|c|c|c|}
\hline Efficacy variable & $\begin{array}{l}\text { ADX10059 } 50 \mathrm{mg} \text { tds, } \\
(\mathrm{n}=12)\end{array}$ & $\begin{array}{l}\text { Placebo tds, } \\
(\mathrm{n}=12)\end{array}$ & p Value \\
\hline $\begin{array}{l}\text { Mean (SD) number reflux episodes } \\
(\mathrm{pH}<4) \text { in } 24 \mathrm{~h}\end{array}$ & $65.3(48.9)$ & $51.9(43.3)$ & NS \\
\hline $\begin{array}{l}\text { Mean (SD) total duration of reflux episodes } \\
(\mathrm{pH}<4) \text { in } 24 \mathrm{~h}(\mathrm{~min})\end{array}$ & $185.3(136.4)$ & $184(172.6)$ & NS \\
\hline $\begin{array}{l}\text { Mean (SD) number nocturnal reflux } \\
\text { episodes }(\mathrm{pH}<4)\end{array}$ & $28.6(26.9)$ & $21.4(20.7)$ & NS \\
\hline $\begin{array}{l}\text { Mean }(\mathrm{SD}) \text { total duration of reflux episodes } \\
(\mathrm{pH}<4) \text { nocturnal period }(\mathrm{min})\end{array}$ & $97.1(76.6)$ & $118(113.3)$ & NS \\
\hline $\begin{array}{l}\text { Mean (SD) number of symptomatic } \\
\text { episodes }\end{array}$ & $5.3(3.3)$ & $6.6(4.6)$ & NS \\
\hline $\begin{array}{l}\text { Mean (SD) duration of symptomatic } \\
\text { episodes (min) }\end{array}$ & 28.7 (43.9) & $43.2(81.0)$ & NS \\
\hline
\end{tabular}

NS, not significant; tds, three times daily.

20:00 to 24:00. Postprandial reflux episodes were documented by a $\mathrm{pH}$ drop to $<4$ for at least $28 \mathrm{~s}$ and as food has an effect on neutralising stomach acid, $\mathrm{pH}$ drops $\geqslant 1$ for at least $28 \mathrm{~s}$ were also used to measure postprandial reflux. The number and duration of postprandial reflux events were summarised for each treatment. In addition, the number and total duration of $\mathrm{pH}$ drops $\geqslant 1$ were summarised for the $24 \mathrm{~h}$ and nocturnal periods.

\section{Clinical symptoms of reflux}

Patients recorded the occurrence and duration of symptomatic reflux episodes in a diary on each treatment day. Patients were asked to note when they experienced typical GORD symptoms. Heartburn and regurgitation were not evaluated separately. The number and duration of symptomatic reflux events were summarised for the $24 \mathrm{~h}$ period.

\section{Safety and pharmacokinetic measures}

Safety assessments were made at screening, at follow-up and at regular time points during the study drug administration days. The safety measures comprised full physical examination, urinalysis, pregnancy testing (screening and follow-up only), heart rate, blood pressure, haematology, biochemistry, 12-lead ECG and regular adverse events enquiry.

Blood samples for plasma concentrations of ADX10059 were taken on both study days (to maintain the blinding to the patient) pre-dose and at $0.5,1.0,2.0,3.0$ and $4.0 \mathrm{~h}$ after each dose. From the plasma concentration versus time profiles the following pharmacokinetic parameters were assessed: $t_{\max }$, $\mathrm{C}_{\max }, \mathrm{AUC}_{0-4}$ and $\mathrm{AUC}_{0-\infty}$.

\section{Statistical methods}

The primary efficacy variable was the percentage of time with oesophageal $\mathrm{pH}<4$ comparing ADX10059 with placebo. Secondary variables included: (1) the percentage of time with oesophageal $\mathrm{pH}<4$ in the nocturnal and diurnal periods; (2) the number and duration of reflux episodes (oesophageal $\mathrm{pH}<4$ ) during the $24 \mathrm{~h}$, nocturnal, and the $4 \mathrm{~h}$ postprandial periods; (3) the number and total duration of $\mathrm{pH}$ drop $\geqslant 1$, during the $24 \mathrm{~h}$, nocturnal and the $4 \mathrm{~h}$ postprandial periods; (4) oesophageal acid clearance; and (5) the number and total duration of symptomatic episodes of GORD.

The analysis populations were as follows. The safety population included all randomised patients, who received the study drug and had post-dosing data. The pharmacodynamic population included all patients who completed the study without major protocol violations or events implying a bias for pharmacokinetic evaluation and with two complete pH-metry profiles (Study Days 1 and 2).

Intra-individual comparison between placebo and active drug was performed during the two successive assessments. Statistical analysis for efficacy was performed on the pharmacodynamic population. For the primary and secondary endpoints, all parameters were analysed on the change from baseline (placebo day 1 value) by analysis of covariance (ANCOVA) using dose level as a fixed effect and baseline as covariate. Estimates (least squares means) of dose effects and differences between doses were provided with their respective 95\% confidence intervals. Quantitative parameters were described per group, dose level and time point using $\mathrm{n}$ (number of observations), mean, median, standard deviation (SD), minimum, and maximum. The $95 \%$ confidence interval of the mean was included for changes from baseline. All statistical tests were two-tailed and the significance threshold was set at the $5 \%$ level.

This was an exploratory study without a formal statistical sample size calculation. A total of 12 patients per dose group was deemed to be sufficient to obtain meaningful data on the pharmacodynamic effect of ADX10059 on $24 \mathrm{~h} \mathrm{pH}$ and clinical symptoms in this proof-of-concept study.

\section{RESULTS}

\section{Patient demographics}

Thirty-two patients were screened, of which 24 were randomised (eight were not eligible, four had abnormal laboratory values, three withdrew consent and one had an abnormal ECG). All 24 randomised patients (12 in Group 1 comparing ADX10059 $50 \mathrm{mg}$ to placebo, and 12 in Group 2 comparing ADX10059 $250 \mathrm{mg}$ to placebo) completed the study and were

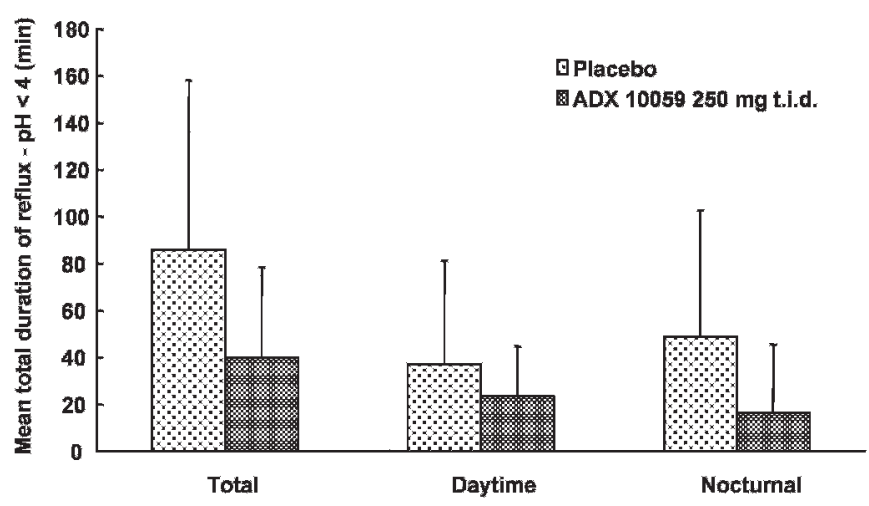

Figure 2 Mean total duration of reflux episodes. 
included in the safety and pharmacokinetic analyses. One male patient in Group 2 was excluded from the pharmacodynamic population due to missing $\mathrm{pH}$-metry data on Study Day 1 when his $\mathrm{pH}$ probe became displaced. Subject disposition is shown in fig 1. The treatment groups had similar demographic and baseline characteristics (table 1)

The majority of the patients were men (nine in Group 1 and 10 in Group 2) with an average age of approximately 45 years. In Group $150 \%$ of patients and in Group $283 \%$ of patients, were previously using regular acid suppression therapy.

\section{Primary efficacy: percentage of time $\mathbf{p H}<\mathbf{4}$ in $\mathbf{2 4} \mathbf{~ h}$}

At baseline, patients in Group 1 tended to have a greater percentage of time $\mathrm{pH}<4$ in the $24 \mathrm{~h}$ period, but this difference was not significant (14.9 (SD 13.9)\% Group 1; 7.2 (SD 5.8)\% Group 2, p = NS). There was no significant effect of ADX10059 $50 \mathrm{mg}$ tds on percentage of time $\mathrm{pH}<4$ (table 2). ADX10059 $250 \mathrm{mg}$ tds significantly decreased the percentage of time that $\mathrm{pH}$ was $<4$ in the $24 \mathrm{~h}$ period to 3.6 (SD 3.2)\% ( $\mathrm{p}=0.0144)$ and in the nocturnal period from 9.7 (SD 10.2)\% to 3.7 (SD 6.0)\% ( $=0.0028)$.

\section{Secondary efficacy measures}

Number and duration of acid reflux episodes: $24 \mathrm{~h}$ and nocturnal periods

At baseline, there were no significant differences between the treatment groups for either the number or total duration of gastro-oesophageal acid reflux episodes during the $24 \mathrm{~h}$ period.

Compared with placebo, ADX10059 $50 \mathrm{mg}$ t.i.d. in Group 1 did not significantly alter the mean number of acid reflux episodes or the total duration of episodes, in all time periods (table 3). The average oesophageal acid clearance was not altered by ADX10059 $50 \mathrm{mg}$ tds (3.9 (SD 0.4) vs 3.4 (SD 0.4) min; NS).

In Group 2, ADX10059 $250 \mathrm{mg}$ tds significantly decreased the mean total duration of acid reflux episodes during the $24 \mathrm{~h}$ period (mean 40 (SD 39) vs placebo 86 (SD 72) min $p=0.0132$ ) and during the nocturnal period (mean 16 (SD 29) vs placebo 49 (SD 54) min, $p=0.0021$ ) (fig 2). There was also a trend towards a decrease in the number of episodes of acid reflux at all time points, but the differences were not statistically significant (table 4). The average oesophageal acid clearance was not significantly altered by ADX10059 $250 \mathrm{mg}$ tds (3.0 (SD 0.3) vs 2.4 (SD 0.3) min, NS).

Total duration $\mathrm{pH}$ drops $\geqslant 1: 24 \mathrm{~h}$ and nocturnal

Overall, in Group 2 there was a reduction in the total duration of $\mathrm{pH}$ drop $\geqslant 1$ in $24 \mathrm{~h}$, from a mean of 118 (SD 57) min with placebo to a mean of 75 (SD 46) min during active treatment $(p=0.054)$ of which the nocturnal duration significantly decreased from a mean of 58 (SD 42) min to a mean of 31 (SD 34) $\min (p=0.0049)$.

In Group 1, the $50 \mathrm{mg}$ dose of ADX10059 did not significantly alter the number or duration of $\mathrm{pH}$ drops $\geqslant 1$ in the postprandial periods, the nocturnal or the $24 \mathrm{~h}$ period.

\section{Postprandial reflux}

In Group 1, the 50 mg dose of ADX10059 did not significantly alter the number or duration of reflux episodes using either oesophageal $\mathrm{pH}<4$, or $\mathrm{pH}$ drops $\geqslant 1$, in the $4 \mathrm{~h}$ postprandial periods.

Using $\mathrm{pH}$ drops $\geqslant 1$, in Group 2 ADX10059 $250 \mathrm{mg}$ tds significantly decreased either the number or duration of reflux episodes in the postprandial periods.

The number of drops of $\mathrm{pH} \geqslant 1$ significantly decreased in the post-breakfast period (mean 6.8 (SD 5.4) vs placebo 9.7 (SD 4.0), $\mathrm{p}=0.041)$. Post-lunch and post-dinner the differences in the number of episodes of $\mathrm{pH}$ drops $\geqslant 1$ were not statistically significant. The duration of $\mathrm{pH}$ drops $\geqslant 1$ significantly decreased in the post-lunch period (mean 8.1 (SD 5.3) vs placebo 15 (SD 8.3) $\min , \mathrm{p}=0.0371$ ) and post-dinner period (mean 5.1 (SD 4.6) vs placebo 13.5 (SD 9.7) $\mathrm{min}, \mathrm{p}=0.0146$ ) (fig 3).

In Group 2, using oesophageal $\mathrm{pH}<4$ to determine postprandial reflux, ADX10059 showed a numerical reduction in the number and duration of episodes but none achieved statistical significance.

\section{Clinical symptoms of reflux}

The mean number of patients who reported symptomatic reflux episodes was significantly lower than the total number of reflux episodes detected by $\mathrm{pH}$ monitoring.

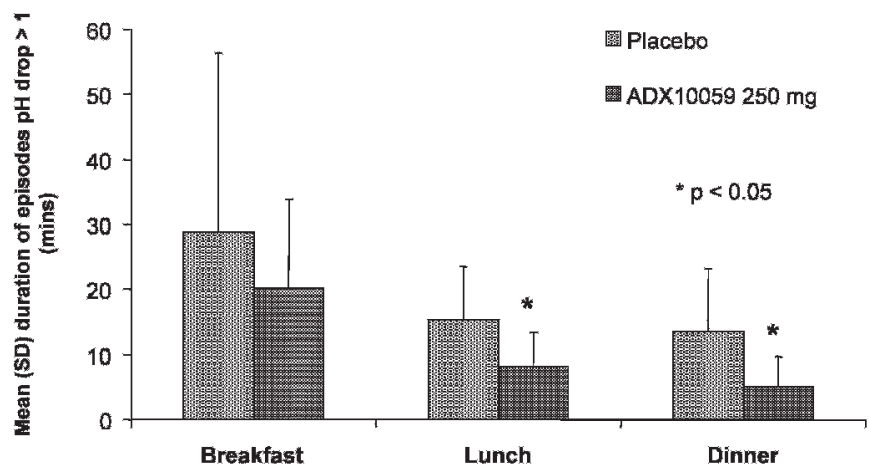

Figure 3 Mean duration of postprandial episodes of $\mathrm{pH}$ drop $>1$.

Table 4 Group 2 (ADX10059 $250 \mathrm{mg}$ tds): number and total duration of reflux episodes and clinical symptoms

\begin{tabular}{llll}
\hline Efficacy variable & $\begin{array}{l}\text { ADX10059 } \mathbf{2 5 0} \mathbf{~ m g ~ t d s ,} \\
(\mathbf{n}=\mathbf{1 1})\end{array}$ & $\begin{array}{l}\text { Placebo tds, } \\
(\mathbf{n}=\mathbf{1 1})\end{array}$ & p Value \\
\hline $\begin{array}{l}\text { Mean (SD) number reflux episodes } \\
(\mathrm{pH}<4) \text { in } 24 \mathrm{~h}\end{array}$ & $20.5(19.4)$ & $32.7(20.3)$ & $\mathrm{NS}$ \\
$\begin{array}{l}\text { Mean }(\mathrm{SD}) \text { total duration of reflux episodes } \\
(\mathrm{pH}<4) \text { in } 24 \mathrm{~h}(\mathrm{~min})\end{array}$ & $39.9(38.7)$ & $86(72.2)$ & 0.0132 \\
$\begin{array}{l}\text { Mean }(\mathrm{SD}) \text { number nocturnal reflux } \\
\text { episodes }(\mathrm{pH}<4)\end{array}$ & $6.4(9.9)$ & $13.6(12.3)$ & $\mathrm{NS}$ \\
$\begin{array}{l}\text { Mean (SD) total duration of reflux episodes } \\
\text { (pH }<4) \text { nocturnal period (min) }\end{array}$ & $16.4(29)$ & $48.7(54)$ & 0.0021 \\
$\begin{array}{l}\text { Mean (SD) number of symptomatic } \\
\text { episodes }\end{array}$ & $1.9(3.8)$ & $7.0(13.8)$ & 0.031 \\
$\begin{array}{l}\text { Mean (SD) duration of symptomatic } \\
\text { episodes (min) }\end{array}$ & $5.2(12.6)$ & $13.9(20.1)$ & 0.031 \\
\hline
\end{tabular}

tds, three times daily. 
ADX10059 $250 \mathrm{mg}$ tds resulted in a statistically significant reduction in the number and duration of symptomatic reflux episodes (table 4). The number of episodes was reduced from 7 (SD 13.8) on the placebo baseline day to 1.9 (SD 3.8) on the active treatment day $(p=0.031)$ and the mean total duration of symptomatic reflux was reduced from 13.9 (SD 20.1) to 5.2 (SD 12.6) $\mathrm{min}(\mathrm{p}=0.031)$ In the ADX10059 $50 \mathrm{mg}$ group, the number of symptomatic episodes was not significantly reduced (table 3 ).

\section{Pharmacokinetics}

The mean plasma concentration-time curves are shown in fig 4. Following oral administration, ADX10059 was rapidly absorbed and was detectable in plasma $30 \mathrm{~min}$ after dosing in the majority of patients. There was inter-individual variability in plasma exposure (coefficient of variation of approx $50 \%$ for both doses for $\mathrm{AUC}_{0-16}$ ). For ADX10059 $50 \mathrm{mg}$, the geometric mean $\mathrm{C}_{\max }$ ranged from $27.3 \mathrm{ng} / \mathrm{ml}$ after dose 1 to $35.4 \mathrm{ng} / \mathrm{ml}$ after dose 3; and for ADX10059 $250 \mathrm{mg}$, ranged from $221 \mathrm{ng} / \mathrm{ml}$ after dose 1 to $283 \mathrm{ng} / \mathrm{ml}$ after dose 3 . The time to reach maximum plasma concentration was variable and ranged between 0.5 and $4 \mathrm{~h}$ regardless of dose and administration number.

Correlations of plasma concentration with reflux episode duration in the whole $24 \mathrm{~h}$ period and in each of the postprandial periods were performed. Although the drug effect seems to increase with increasing ADX10059 dose, no clear pharmacodynamic/pharmacokinetic relationship could be seen.

\section{Safety and tolerability}

ADX10059 given as three doses in 1 day was generally well tolerated by the patients with GORD. No serious adverse events were reported. One patient in Group 1 reported flatulence after receiving placebo. The incidence of adverse events was higher in Group 2, the $250 \mathrm{mg}$ tds group, 11/12 (91.6\%) than in the $50 \mathrm{mg}$ t.i.d. group 2/12 (16.7\%). In Group 1, somnolence, cough and rhinorrhoea were reported in $1 / 12$ patients (8\%). In Group 2, the most commonly reported adverse events were related to the central nervous system and the most common single adverse event was dizziness ( $9 / 12$ patients, $75 \%$ ). The dizziness was accompanied by nausea in $4 / 12(33 \%)$ of the patients. In addition, 2 (17\%) patients reported dysuria and other events occurring in 1/12 (8\%) patients were tinnitus, visual accommodation disorder, dry mouth, vomiting, paresthesia, hypoesthaesia, feeling drunk and hot flush. All adverse events except one occurred following the first or second dose; none of the events was described as severe and all resolved without sequelae. No clinically significant changes in safety monitoring parameters for haematology, blood chemistry, urinalysis, vital signs, physical examination or 12-lead ECG were reported.

\section{DISCUSSION}

Inhibition of mGluR5 has been shown to reduce transient lower oesophageal sphincter relaxation episodes and increase lower oesophageal sphincter tone in animals, ${ }^{12}{ }^{13}$ a mechanism which could have application in the prevention of gastro-oesophageal reflux in humans. To our knowledge, the effect of mGluR5 inhibition on TLOSRs and reflux events has not been reported in humans. The aim of the present study was to assess the effect of ADX10059 on gastro-oesophageal reflux in patients with GORD, using pH-metry to detect episodes of acid reflux and hence indirectly study LOS function.

To this end, 24 patients with GORD diagnosed in a specialist gastroenterology clinic were randomised in two groups of 12 patients (Groups 1 and 2). In each group, the effect of
ADX10059 (50 mg tds or $250 \mathrm{mg}$ tds for 1 day) was compared with placebo. The doses of ADX10059 were selected based upon the pharmacokinetic and tolerability data from a previous repeated dose study in healthy subjects (ref study ADX10059102 data on file). The upper and lower extremes of the doses from that study were chosen for this study to explore the safety, tolerability and pharmacodynamics across a dose range that might have therapeutic potential in patients with GORD. In both groups, each patient received placebo treatment on Day 1 and then ADX10059 on Day 2 in a single-blind fashion, and therefore acted as his/her own control. Patients were blinded as to the treatment sequence so that they could objectively evaluate their clinical symptoms on each treatment day.

Consistent with previous results obtained with the immediate release, powder-filled capsule, ADX10059 was quite rapidly absorbed with a median plasma peak occurring between 1.0 and $2.0 \mathrm{~h}$ following administration. As already observed in healthy subjects, there was a large inter-individual variability for plasma concentrations and pharmacokinetic parameters. No clear relationship was drawn from the review of drug exposure and drug effect. The safety and tolerability profile was also consistent with that observed at these doses in previous single and repeated dose studies of ADX10059 in healthy subjects (refs. Data on file, studies ADX10059-101, 102 and 103). The central nervous system effects (eg, dizziness) seen in the $250 \mathrm{mg}$ tds group are consistent with the mechanism of action and the rapid absorption following dosing using the immediate release capsule. The side effect profile in the higher dose group is considered undesirable for long-term treatment of GORD, therefore a modified release formulation which is less rapidly absorbed and which has been shown to reduce the occurrence of central nervous system side effects (data on file Study ADX10059-104), has been developed and will be used for subsequent studies. While the $50 \mathrm{mg}$ of ADX10059 tds had no statistically significant effect, the $250 \mathrm{mg}$ dose of ADX10059 tds produced significant improvement in $\mathrm{pH}$-metry-derived reflux and in the symptomatic expression of GORD. To our knowledge, this is the first study in humans to support the findings of previous animal studies on the effect of mGluR5 antagonism on reflux events. Hence the concept that the mGluR5 negative allosteric modulator (NAM) may reduce reflux and have therapeutic potential in GORD was supported by the findings of this study.

Based on animal studies with other mGluR5 NAMs, 3-[(2-methyl-1,3-thiazol-4-yl)ethynyl]pyridine (MTEP) and 2-methyl-6-phenylethynylpyridine (MPEP), the effects of ADX10059 on oesophageal acid exposure are expected to reflect inhibition of TLOSRs through a peripheral mode of action. ${ }^{10}$ The decrease in acid reflux events in the postprandial period, when TLOSRs occur most frequently, ${ }^{9}$ is compatible with such a mechanism of action. It is less clear whether the inhibition of nocturnal reflux events is also attributable to inhibition of TLOSRs, or whether other factors, such as an increase in resting LOS pressure which was apparent from animal studies using MTEP and MPEP, ${ }^{12}$ may play an additional role. Inhibition of nocturnal reflux has also been observed with baclofen, which inhibits TLOSRs through $\gamma$-amino butyric acid type B receptor agonism. ${ }^{91617}$ Although the $250 \mathrm{mg}$ dose of ADX10059 significantly decreased the total duration of acid reflux events, this was not associated with a significant decrease of the number of reflux events for the $24 \mathrm{~h}$ measurement period. This observation suggests shortening of reflux episodes, which could be due to improved oesophageal clearance (although this was not observed in this study) or to a smaller volume of refluxed material during reflux events. Elucidating the mechanisms 
Figure 4 Mean plasma concentration versus time profiles following repeated oral doses three times daily of $50 \mathrm{mg}$ or $250 \mathrm{mg}$ of ADX10059 for 1 day (linear scale).
ADX10059



underlying the anti-reflux effects of ADX10059 will require additional studies.

This study was an initial exploratory study and as such the authors recognise that there are features of the design which could potentially impact the interpretation of the results and for which the rationale should be explained. A single-blind sequential day dosing regimen was chosen principally for logistic reasons, so that the patients would not have to undergo $\mathrm{pH}$ monitoring for an extended duration or have to undergo repeated admissions to the unit, which would have been required if the study had been a randomised cross-over design. The patients were blinded to the treatment sequence and underwent exactly the same procedures on Study Days 1 and 2 (including blood sampling for pharmacokinetics) in order to minimise any effect on subjective symptom reporting. As the majority of evaluations were objective physiological measures, the single-blind design should not affect these. However, it is possible that the measures on Study Day 2 could differ to those on Study Day 1 due to the study conditions and it would normally be preferable to randomise the treatment order to mitigate this. Overall, using the $250 \mathrm{mg}$ dose, significant decreases in acid reflux parameters and in reflux-related symptoms were observed. Although oesophageal $\mathrm{pH}$ monitoring shows considerable intra-individual day-to-day variability, systematic order effects with lower acid exposures on Study Day 2 are not found. ${ }^{18-27}$ Also, the consistent effects in the $250 \mathrm{mg}$ dose group were not seen in the $50 \mathrm{mg}$ dose group suggesting a dose response effect. Hence the study design is not considered to significantly impact the overall interpretation of the results.

The definition of reflux events as seven consecutive episodes of oesophageal $\mathrm{pH}<4$ was one that was standard for the clinical pharmacology unit. It is recognised that this may lead to underreporting of the number of reflux events and only acid reflux events can be captured in this way. The total percentage of $\mathrm{pH}<4$ was derived from the continuous $\mathrm{pH}$ monitoring and so reflux events that were less than $28 \mathrm{~s}$ were captured in this measurement. Furthermore, as food may neutralise the stomach $\mathrm{pH}$, drops in $\mathrm{pH}$ of $\geqslant 1$ for $\geqslant 28 \mathrm{~s}$ were used, in addition to the measure of $\mathrm{pH}<4$ for $\geqslant 28 \mathrm{~s}$, to more accurately identify postprandial reflux events. Impedance $\mathrm{pH}$ monitoring is a more sensitive measure of reflux events capturing all types of reflux event and this will be used for subsequent studies.

\section{CONCLUSIONS}

To our knowledge, this is the first study to report on the effects of a mGluR5 NAM in patients with GORD. ADX10059 $250 \mathrm{mg}$ tds reduced acid reflux as measured by $\mathrm{pH}$-metry, and this was associated with improvement in clinical symptoms. The study confirms the potential for the mGluR5 NAM ADX10059 in the treatment of GORD. Potential therapeutic applications to be evaluated include add-on therapy in patients with GORD with incomplete response to PPIs, or monotherapy in those for whom PPIs are unsuitable.

Acknowledgements: The authors would like to thank Dr B Elharrar who acted as the principal investigator, Dr E Evène who was responsible for the analysis of the $\mathrm{pH}$ traces and B Néau who performed the statistical analysis of the results.

Funding: Addex Pharma was the sponsor of this study and determined the design.

Ethics approval: Approval was given by the Ethics Committee (CPP) of Robert Ballanger Hospital, Aulnay-sous-Bois, on 10 July 2006.

Clarifications: The statistical analysis of the entire data sets pertaining to efficacy (specifically primary and secondary major efficacy endpoints) and safety have been independently confirmed by a biostatistician who is not employed by the corporate entity.

CK had full access to all of the data and takes full responsibility for the veracity of the data and analysis.

Data collection and analysis was performed by a clinical research facility.

Data interpretation was performed by JT.

\section{REFERENCES}

1. Vakil N, van Zanten SV, Kahrilas P, et al., and the Global Consensus Group.The Montreal definition and classification of gastro-esophageal reflux disease: a global evidence-based consensus. Am J Gastroenterol 2006;101:1900-20.

2. Moayyedi P, Talley NJ. Gastro-esophageal reflux disease. Lancet 2006;367:2086-100.

3. Chiba N, De Gara CJ, Wilkonson JM, et al. Speed of healing and symptom relief in grade II to IV gastro-esophageal reflux disease: A meta-analysis. Gastroenterology 1997;112:1798-810.

4. Holloway RH, Dent J, Narielvala F, et al. Relation between esophageal acid exposure and healing of oesophagitis with omeprazole. Gut 1996;38:649-54.

5. Klinkenberg-Knol EC, Meuwissen SGM. Combined gastric and esophageal 24-h $\mathrm{pH}$ monitoring and esophageal manometry in patients with reflux disease resistant to treatment with omeprazole. Aliment Pharmacol Ther 1990; 4:485-95

6. Katzka DA, Paoletti V, Leite L, et al. Prolonged ambulatory pH monitoring in patients with persistent gastro-esophageal reflux disease symptoms: Testing while on therapy identifies the need for more aggressive anti-reflux therapy. Am J Gastroenterol 1996;91:2110-3.

7. Fass R, Mackel C, Sampliner RE. 24-h pH monitoring in symptomatic patients without erosive esophagitis who did not respond to antireflux treatment. J Clin Gastroenterol 1994;19:97-9.

8. Leite LP, Johnston BT, Just RJ, et al. Persistent acid secretion during omeprazole therapy: A study of gastric acid profiles in patients demonstrating failure of omeprazole therapy. Am J Gastroenterol 1996:9:1527-31.

9. Tack J. Recent developments in the pathophysiology and therapy of gastroesophageal reflux disease and non-erosive reflux disease. Curr Opin Gastroenterol 2005:21:454-60.

10. Young RL, Page AJ, O'Donnell TA, et al. Peripheral versus central modulation of gastric vagal pathways by metabotropic glutamate receptor 5. Am J Gastrointest Liver Physiol 2007;292:G501-11. 
11. Page AJ, Young RL, Martin CM, et al. Metabotropic glutamate receptors inhibit mechanosensitivity in vagal sensory neurons. Gastroenterology 2005;128:402-10.

12. Frisby CL, Mattsson JP, Jensen JM, et al. Inhibition of transient lower esophageal sphincter relaxation and gastro-esophageal reflux by metabotropic glutamate receptor ligands. Gastroenterology 2005;129:995-1004.

13. Jensen J, Lehmann A, Uvebrant A, et al. Transient lower esophageal sphincter relaxations in dogs are inhibited by a metabotropic glutamate receptor 5 antagonist. Eur J Pharmacol 2005;519:154-7.

14. Shigemoto R, Nakanishi S, Mizuno N. Distribution of the mRNA for a metabotropic glutamate receptor (mGluR1) in the central nervous system: an in situ hybridization study in adult and developing rat. J Comp Neurol 1992;322:121-35.

15. Romano C, Sesma MA, McDonald CT, et al. Distribution of metabotropic glutamate receptor mGluR5 immunoreactivity in rat brain. J Comp Neurol 1995;355:455-69.

16. Koek GH, Sifrim D, Lerut $T$, et al. Effect of the $G A B A(B)$ agonist baclofen in patients with symptoms and duodeno-gastro-esophageal reflux refractory to proton pump inhibitors. Gut 2003:52:1397-402.

17. Ciccaglione AF, Marzio L. Effect of acute and chronic administration of the GABA B agonist baclofen on 24 hour pH metry and symptoms in control subjects and in patients with gastro-oesophageal reflux disease. Gut 2003;52:464-70.

18. Wiener GJ, Morgan TM, Copper JB, et al. Ambulatory 24-hour esophageal pH monitoring. Reproducibility and variability of $\mathrm{pH}$ parameters. Dig Dis Sci 1988; 33:1127-33.
19. Jamieson JR, Stein HJ, DeMeester TR, et al. Ambulatory 24-h esophageal pH monitoring: normal values, optimal thresholds, specificity, sensitivity, and reproducibility. Am J Gastroenterol 1992;87:1102-11.

20. Nielsen RG, Kruse-Andersen S, Husby S. Low reproducibility of $2 \times 24$-hour continuous esophageal $\mathrm{pH}$ monitoring in infants and children: a limiting factor for interventional studies. Dig Dis Sci 2003;48:1495-502.

21. Pandolfino JE, Richter JE, Ours T, et al. Ambulatory esophageal pH monitoring using a wireless system. Am J Gastroenterol 2003;98:740-9.

22. Prakash C, Clouse RE. Value of extended recording time with wireless $\mathrm{pH}$ monitoring in evaluating gastro-esophageal reflux disease. Clin Gastroenterol Hepatol 2005;3:329-34.

23. Tseng D, Rizvi AZ, Fennerty $\mathrm{MB}$, et al. Forty-eight-hour pH monitoring increases sensitivity in detecting abnormal esophageal acid exposure. J Gastrointest Surg 2005;9:1043-51.

24. Ahlawat SK, Novak DJ, Williams DC, et al. Day-to-day variability in acid reflux patterns using the BRAVO pH monitoring system. J Clin Gastroenterol 2006:40:20-4.

25. Bechtold ML, Holly JS, Thaler K, et al. Bravo (wireless) ambulatory esophageal pH monitoring: how do day 1 and day 2 results compare? World J Gastroenterol 2007:13:4091-5.

26. Gunnarsdóttir A, Stenström P, Arnbjörnsson E. 48-Hour wireless esophageal pHmonitoring in children: are two days better than one? Eur J Pediatr Surg 2007;17:378-81.

27. Wenner J, Johansson J, Johnsson F, et al. Optimal thresholds and discriminatory power of 48-h wireless esophageal $\mathrm{pH}$ monitoring in the diagnosis of GERD. Am J Gastroenterol 2007:102:1862-9.

\section{Editor's quiz: GI snapshot}

\section{ANSWER}

From the question on page 1176

The patient was referred to surgery for a suspected submucosal gastric intestinal stromal tumour (GIST) that was arising from the muscularis layer of the gastric wall. Intraoperatively, the mass was found to be adherent to the undersurface of the left lobe of the liver which mandated an en bloc left lateral segmentectomy and wedge gastrectomy. Pathological examination of the resected specimen confirmed heterotopic pancreatic tissue in the gastric wall, composed of pancreatic acini and ducts with no islets, involving the submucosa and muscularis propria with an intact overlying mucosa (fig 1). The pancreatic tissue displayed all the changes of acute pancreatitis. Heterotopic pancreas (HP) is the second most common pancreatic congenital anomaly after divisum. ${ }^{1}$ It has an incidence of $0.6-15 \%$ in autopsy series and is found incidentally in 1 of 500 laparotomies. ${ }^{1} \mathrm{HP}$ is located within the upper gastrointestinal tract in $70-90 \%$ of cases. ${ }^{1}$ Histologically, the aberrant pancreatic tissue may contain all elements of normal pancreatic tissue such as acini, ducts and islet cells. ${ }^{2}$ Consequently, HP may demonstrate the full range of pancreatic pathologies including pancreatitis (acute and chronic) as well as benign and malignant neoplastic transformations. ${ }^{2}$

Gut 2009;58:1199. doi:10.1136/gut.2008.173773a

\section{REFERENCES}

1. Eisenberger CF, Gocht A, Knoefel WT, et al. Heterotopic pancreas-clinical presentation and pathology with review of the literature. Hepatogastroenterology 2004; 51:854-8.

2. Rodrigues FJ, Abraham SC, Allen MS, et al. Fine-needle aspiration cytology findings from a case of pancreatic heterotopia at the gastroesophageal junction. Diagn Cytopathol 2004;31:175-9.
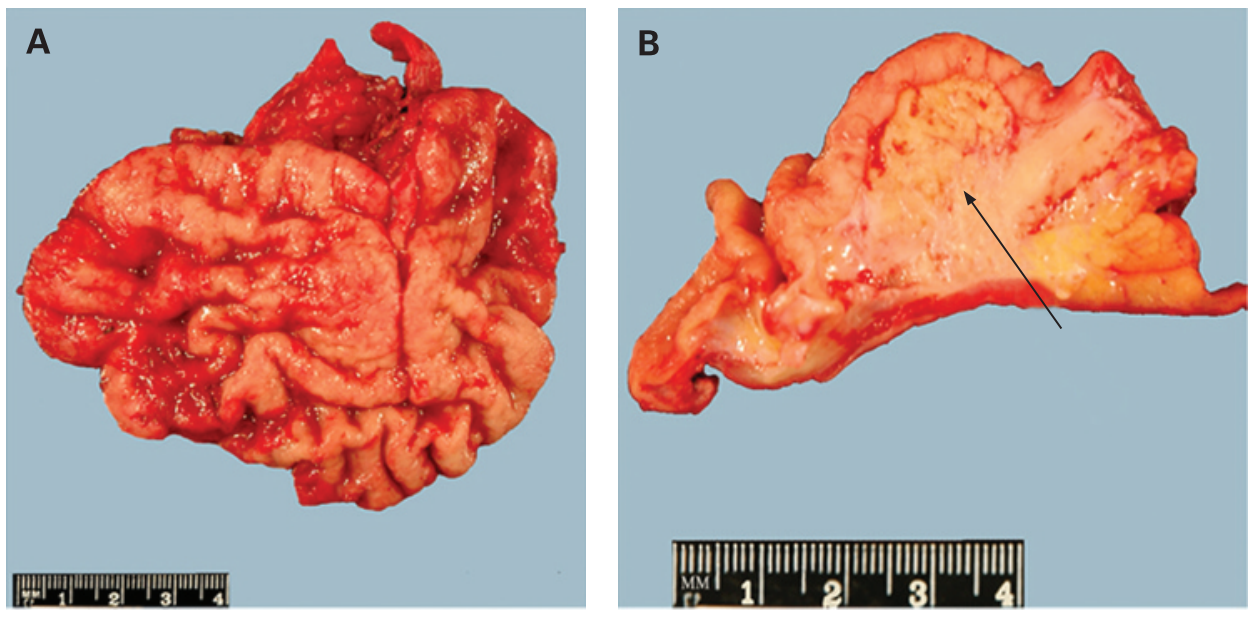

Figure 1 Partial gastrectomy specimen. (A) The submucosal bulge. (B) Cross-sectional view of the resected stomach showing the heterotopic pancreatic tissue (arrow) within the layers of the gastric wall. 